\title{
Stink and Sheen of Waste: An Effort to Empowering the Scavenger
}

\author{
Rusydan Fathy* \\ Research Center for Society and Culture - Indonesian Institute of Sciences (PMB - LIPI), Indonesia
}

Submission: March 27, 2019; Published: April 04, 2019

*Corresponding author: Rusydan Fathy, Research Center for Society and Culture - Indonesian Institute of Sciences (PMB - LIPI), Jakarta, Indonesia

\section{Opinion}

Based on data from the Badan Pusat Satatistik Indonesia (BPS/Indonesian Central Statistics Agency), the level of urbanization in Indonesia reached $49.8 \%$ in 2010 and is predicted to reach $60 \%$ by 2020 . Meanwhile, Jakarta has a population of more than 10 million people with an area of only 661.5 square kilometers. It is estimated, in 2040 the population of Jakarta will be at 11.28 million. With this fact, it raises several problems in Jakarta that have not been able to be resolved optimally, such as congestion, settlements and poverty. The high number and level of population density in Jakarta seems to produce chaos for the city. With such a portrait, one of the efforts of the DKI Jakarta Provincial Government is to improve the matter of urban spatial planning. In Jakarta, it can easily identify the symptoms of poverty that are related to spatial issues -settlements. The bags of slums are located in the corners of the city, side by side with dozens of floors of buildings. Those who are classified as poor in Jakarta inhabit improper settlements such as on the edge of a railroad crossing or on the outskirts of a watershed. Another sight that can be easily seen is the wild buildings that were built by scavengers as a place to live.

Residents with high density in an area seem to influence the high volume of waste produced, including in Jakarta. The series of problems caused by the high volume of waste in Jakarta later became a complement to the problems that exist in urban areas as mentioned above. However, waste has economic value for some people in the midst of the exclusive world of formal work. As intended, emerging professions that are identical to waste in Jakarta, such as scavengers. Related to this, the Chair of the Asosiasi Pelapak dan Pemulung Indonesia (APPI/Indonesian Association of Scrapers and Scavengers), Bagong Suyoto, on one occasion interviewed by the author, saying that "Trash is a treasure". We are faced with the fact that when waste production is constantly increasing, there is also an increase in the waste picking profession at the level of the informal economy. The informal economy itself is certainly a cornerstone of the people's economic drive (Based on BPS data in 2018, as many as $58.22 \%$ or 73.93 million Indonesians depend on the informal economy). The condition of increasing waste production, it seems, is also considered an alternative livelihood opportunity, given the limited knowledge and skills needed to access formal employment.

Without the need to present statistical data, if enough for the community to feel there will be an increase in the number of scavengers in urban areas. Inevitably, it seems that scavengers are indeed synonymous with waste and poverty. Waste and poverty, however, are blurred portraits of urban glitter. In fact, the community has legitimized waste collectors as one of the disadvantaged groups that occupies the lowest strata of the community. In the end, an increase in the number of people who work as scavengers represents a problem of welfare in urban areas. It is interesting to observe when scavengers are considered a problem that arises from a problem (waste). However, both can be said to be causal relationships. In fact, armed with good optimism and prejudice, it can be said that scavengers exist by having a single goal -managing waste. Scavengers, reflecting the concrete actions of the reduce, reuse and recycle slogan. These objectives and functions provide confirmation of the existence of scavengers in the sustainability and balance of urban life. In the midst of the stigma towards scavengers, the profession has actually become a kind of three-quarter money by solving waste problems in urban areas. In the midst of marginalization, scavengers actually contribute to environmental conservation efforts. If so, the question that arises is how to place the position of waste collectors as a community that plays a role in solving environmental problems? In addition, how should the state empower scavengers in order to eliminate social exclusion or marginalization (marginalization) that they experience?

Basically, if managed waste has tremendous benefits in order to reduce environmental burdens which are increasingly alarming. Based on BPS data, in 2016 the number of landfills in Indonesia reached more than 65 million tons per year with a population of more than 260 million people. According to 
the World Bank, it is estimated that in 2025 there will be an increase of up to 4.3 billion urban residents who produce around $1.42 \mathrm{~kg}$ per person per day of municipal solid waste (2.2 billion tons per year). This waste buildup creates various environmental problems such as pollution (water and air) and disaster (flood). The results of the 2014 and 2018 Village Potential Survey show an increase in water pollution and a decrease in air quality. According to Hooenweg and Bhada in "What is Waste: A Global Review of Solid Waste Management", waste piles produce toxic liquid runoff called leachate - flowing into rivers, groundwater and soil, reducing the amount of oxygen available and encouraging the growth of dangerous organisms. Meanwhile, based on BNPB data, throughout 2016-2017, floods (one of which was waste) that hit Indonesia were 1805 incidents with 433 victims. In addition, based on BPS data, the number of deaths from diarrhea in 2016 was at 3.04 percent (even though what was expected was below 1 percent).

In the midst of a bad image of solid waste, waste actually presents economic gains for certain groups of people, including scavengers. Scavengers live from waste to support their families. If referring to the definition of the Kamus Besar Bahasa Indonesia (KBBI/ Indonesia Dictionary), scavengers are people who make a living by searching for and collecting and utilizing used goods by selling them to entrepreneurs (pelapak) who will process them back into commodity goods. Therefore, it is necessary to highlight the pattern of relations between scavengers, pelapak and other related parties in managing waste. The attractiveness of the city and the motivation of individuals reinforce the intention to fight with the provision of low human resources. Only with makeshift skills and kinship networks, is enough to make them confident to be able to survive in Jakarta. For scavengers and other community groups such as parking lots, street vendors and even beggars, they still consider their lives to be better after living in Jakarta. The minimum income they earn from the waste collection is actually able to support themselves and income earned during the year.

Economic turnover in urban areas and the proliferation of opportunities for the informal sector (including being scavengers) really become a magnet for migrants to bring economic coffers. Furthermore, it is not a secret if only a handful of people favor national economic growth at the height of social stratification. This is of course not useful for scavengers and other marginal groups of people as long as they are able to obtain a small amount of fixed income. More than that, still income is a certainty and an opportunity that is unfortunately missed. Those who live in the lower strata of social stratification will not just miss the compilation they know, that they will get nothing more to compile their lives in the village. Another factor that makes scavengers able to survive is because they have social capital. Communities do not have the potential for social capital -relations that have the power to obtain economic benefits and social benefits. Many scavengers in the city are affiliated in a scavenger community which is a place for them to carry out their activities. From their joining to daily operations, the community of course has provided scavengers to achieve common goals.

Observations and interviews with Bagong Suyoto showed that he had good social capital. As Putnam, the Bonding Social Capital and Bridging Social Capital are well utilized by many scavenger communities. The shared identity agreed to by the tribe and fate is a Bonding Social Capital scavenger that makes them have feelings as a one unity. Moreover, this Social Capital Association provides access and information that smoothest the sustainability of their activities. The Social Capital Association in the scavenger community is able to change personal interests and competition into social cooperation. Patronage relations between the head of scavengers and scavengers in a community also show a good Social Capital. They do not just economic exchange, diverting what is called Fukuyama in The Great Disruption - moral exchange. Moral exchange takes place based on shared identity and values. Fukuyama explained, how to transfer morals that are different from the economy when conducting direct and simultaneous transactions. In morale, the party that does not expect an imbalance from what is done now to the other party, but with full and conscious conviction, then he will get pleasure or profit in the future. Moreover, the moral exchange takes place informally, while still giving a strong commitment to each party.

In the context of the life of the scavenger community, it is usually preceded by the release (purchase) of vacant land by people who will later become the leaders of the scavenger community. After that, he usually began to form a scavenger community by recruiting scavengers informally based on kinship and recommendations from previous members. For those who want to become scavengers, of course joining a community like this provides benefits. At the very least, they can occupy the building provided by the landowner as a place to live and store their harvest. More than that, although sometimes landowners (who are also head of scavengers) create informal rules unilaterally, but this does not rule out the possibility of being jointly decided. For scavengers who live in a community, informal rules related to work patterns that are applied are not considered as barriers or restraints, on the contrary, they are considered to provide order. Meanwhile, Bridging Social Capital in a community plays a role in expanding internal cooperation towards external cooperation. The pattern of relations and activities of scavengers that are accommodated by the community reflects their form of coordination with entrepreneurs and the government. This usually depends on the capacity of the social network owned by the scavenger leader to other parties.

The problems faced by scavenger communities are usually due to their weak bargaining position towards other parties. For example, the scavenger community often does not act because it cannot determine the price of the collection of used goods because 
it is determined by the pelapak. This becomes worse when the pelapak sets a very low price for the work of scavengers. In fact, if likened to garbage is a treasure, scavengers are the people closest to the property. Ironically, as Bagong Suyoto revealed, scavengers are actually under the chain of economic structures. Furthermore, according to Bagong, the associations which claim to be the scavengers' ties do not contribute anything to the improvement of the welfare of scavengers. According to Bagong, these associations have failed, even in protecting scavengers from moneylenders. Another problem related to the existence of scavengers is the stigma attached to it. The community considers that waste collectors are merely social problems that must be addressed immediately. Scavenger activities are considered illegal and illegal which disturbs the landscape and order. In fact, if someone is dedicated every day to cleaning up other people's garbage, he is a scavenger. According to Bagong, scavengers are heroes of the 3R program (reduce, reuse, and recycle) mandated by the Law on Waste Management in Indonesia. Unfortunately, the government was ignorant and paid little attention to the activities and space for scavengers.

The existence of scavengers in the context of this discussion can be concluded to include into 3 dimensions, namely economic, environmental, and socio-cultural. In the economic dimension, we agree that becoming waste collectors is an alternative choice for many informal sectors in urban areas. In the environmental dimension, it is clear that the scavenger activity is basically an extension of the $3 \mathrm{R}$ program which means the Law. In the sociocultural dimension, the scavenger community is considered to have the potential for social capital which is always used to bring economic benefits and social benefits. However, one dimension that might be forgotten is the policy dimension. Both in the economic, environmental, and socio-cultural dimensions, scavengers have problems that have to be solved. Therefore, the role of government is very important in the context of the policy dimension. The government must strive to eliminate social exclusion - that is, the condition is directed at weakening capacity in various aspects of life faced by scavengers. Excluded, meaning that waste collectors have limited access, participation and freedom in terms of service, rights and basic life needs. The first thing the government can do of course is to prioritize the empowerment of scavengers through a bottom-up policy scheme.

Bottom-up policies are policies that seek to involve the community. In this policy, the community is placed not only as a policy target, but also as a subject of policy. The community will be given the freedom to express their aspirations. It is hoped that the community will be able to raise the things that really become their problems and the government will listen to the solutions offered and become the people's wishes. Both academics and practitioners call such a policy paradigm in terms of community-based policies with the aim of empowering them. Later, we prefer to use the concept of inclusive development to illustrate a development that involves all related elements and synergize with each other for the sake of creating an inclusive social environment - a social environment that invites everyone to create prosperity and happiness for them.

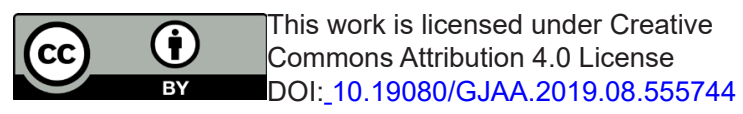

\section{Your next submission with Juniper Publishers will reach you the below assets}

- Quality Editorial service

- Swift Peer Review

- Reprints availability

- E-prints Service

- Manuscript Podcast for convenient understanding

- Global attainment for your research

- Manuscript accessibility in different formats

( Pdf, E-pub, Full Text, Audio)

- Unceasing customer service

Track the below URL for one-step submission https://juniperpublishers.com/online-submission.php 